\title{
Prediction of indicators of cow diet composition and authentication of feeding specifications of Protected Designation of Origin cheese using mid-infrared spectroscopy on milk
}

\author{
M. Coppa, ${ }^{1 *}$ B. Martin, ${ }^{1}$ S. Hulin, ${ }^{2}$ J. Guillemin, ${ }^{3}$ J. V. Gauzentes,${ }^{4}$ A. Pecou, ${ }^{5}$ and D. Andueza ${ }^{1}$ \\ ${ }^{1}$ Université Clermont Auvergne, INRAE, VetAgro Sup, UMR 1213 Herbivores, F-63122 Saint-Genès-Champanelle, France \\ ${ }^{2}$ Pôle Fromager AOP Massif Central, 20 Côte de Reyne, F-15000 Aurillac, France \\ ${ }^{3}$ Cantal Conseil Elevage, 26 Rue du 139ème Régiment d'Infanterie-BP 239, F-15002 Aurillac \\ ${ }^{4}$ Agrolab, 38 Rue de Salers, F-15000 Aurillac, France \\ ${ }^{5}$ Centre National Interprofessionnel de l'Economie Laitière (CNIEL), 42 Rue de Châteaudun I, F-75314 Paris, France
}

\begin{abstract}
The ability of mid-infrared spectroscopy (MIR) to predict indicators (1) of diet composition in dairy herds and (2) for the authentication of the cow feeding restrictions included in the specification of 2 Protected Designation of Origin (PDO) cheeses (Cantal and Laguiole) was tested on 7,607 bulk milk spectra from 1,355 farms located in the Massif Central area of France. For each milk sample, the corresponding cow diet composition data were obtained through on-farm surveys. The cow diet compositions varied largely (i.e., from full grazing for extensive farming systems to corn silage-based diets, which are typical of more intensive farming systems). Partial least square regression and discriminant analysis were used to predict the proportion of different feedstuffs in the cows' diets and to authenticate the cow feeding restrictions for the PDO cheese specifications, respectively. The groups for the discriminant analysis were created by dividing the data set according to the threshold of a specific feedstuff. They were issued based on the specifications of the restriction of the PDO cheese. The pasture proportion in the cows' diets was predicted by MIR with an coefficient of determination in external validation $\left(R^{2} \mathrm{~V}\right)$ $=0.81$ and a standard error of prediction of $11.7 \%$ dry matter. Pasture + hay, corn silage, conserved herbage, fermented forage, and total herbage proportion in the cows' diets were predicted with a $\mathrm{R}^{2} \mathrm{~V}>0.61$ and a standard error of prediction $<14.8$. The discrimination models for pasture presence, pasture $\geq 50 \%$, and pasture $\geq 57 \%$ in the cows' diets achieved an accuracy
\end{abstract}

Received March 4, 2020.

Accepted August 17, 2020.

*Corresponding author: mauro.coppa@inrae.fr and specificity $\geq 90 \%$. A sensitivity and precision $\geq 85 \%$ were also observed for the pasture proportion discrimination models, but both of these indexes decreased at increasing thresholds from 0 to 50 , and $57 \%$ pasture in the cows' diets. An accuracy $\geq 80 \%$ was also observed for pasture + hay $\geq 72 \%$, herbage $\geq 50 \%$, pasture + hay $\geq 25 \%$, absence of fermented herbage, absence of corn silage, and corn silage $\leq 30 \%$ in the cows' diets, but for several models, either the sensitivity or precision was lower than the accuracy. Models built on the simultaneous respect of all the criteria of the feeding restrictions of PDO cheese specifications achieved an accuracy, specificity, sensitivity, and precision $>90 \%$. Both the regression and discriminant MIR models for bulk milk can provide useful indicators of cow diet composition and PDO cheese specifications to producers and consumers (farmers, dairy plants).

Key words: mid-infrared spectroscopy, milk, cow feeding authentication, PDO cheese

\section{INTRODUCTION}

Authentication of farming practices through rapid analyses of products has been a concern of many dairy production chains for several years. This has especially been a concern for European Protected Designation of Origin (PDO) cheeses, whose specifications require restrictions in farming practices related in particular to animal feeding. As such certifications often add value to products, producers need tools to check and strengthen the commitments made with consumers through labels and specifications. Animal feeding is considered one of the main factors affecting milk and cheese composition (Cabiddu et al., 2019), and sensory properties (Giaccone et al., 2016; Bergamaschi et al., 2020). Thus, several studies for the authentication of feeding systems on dairy products have been conducted in recent decades and recently reviewed by Prache et 
al. (2020). Among others, Vicente et al. (2017), Hurtaud et al. (2014), and Mitani et al. (2016) successfully used milk fatty acids (FA) to authenticate cow feeding systems. Vitamins and carotenoids in milk were used to authenticate pasture feeding of cows (Segato et al., 2017), and volatile organic compounds were tested for authentication purposes (Valdivielso et al., 2017; Bergamaschi et al., 2020). Auerswald et al. (2015) and Valenti et al. (2017) proposed stable isotopes for cow feeding authentication. However, among the various authentication tools, Prache et al. (2020) identified infrared spectroscopy techniques as the most promising methods due to their rapidity and low cost, which allow for routine application, as well as for their accurate performances, which are often similar to those of reference methods used for authentication purposes. Nearinfrared spectroscopy (NIR) was successfully used on cheese (Ottavian et al., 2012; Andueza et al., 2013) and milk (Coppa et al., 2012) for authentication of farming practices. Andueza et al. (2013) and Coppa et al. (2012) authenticated cow feeding regimens with reliable results. Furthermore, mid-infrared spectroscopy (MIR) was applied on bulk milk from commercial farms with promising results (Valenti et al., 2013; Capuano et al., 2014) for authenticating feeding systems. However, these studies compared contrasting feeding systems. Diets with intermediates and variable proportions of feedstuffs, which are typical on commercial farms, are expected to increase the incertitude of milk classification, as observed with NIR (Coppa et al., 2012). For this reason, a predictive approach of the proportion of different feedstuffs in cows' diets would be interesting for authentication purposes. Only Klaffenböck et al. (2017) proposed this approach using MIR on individual cow milk samples from experimental farms, but with only partially successful results $\left(\mathrm{R}^{2}\right.$ in validation $<0.43$, except for pasture proportion $\mathrm{R}^{2}$ in validation $=0.66$ ). Mid-infrared spectroscopy is routinely used in Europe for the prediction of bulk milk composition (i.e., milk fat and protein contents, and so on) used for milk payment. However, MIR models to predict indicators of cow diet composition developed on bulk milk from commercial farms are still lacking. Similarly, MIR has never been tested on milk to develop indicators able to check adherence to PDO cheese specifications related to cow feeding.

The aims of this work were to test the ability of MIR on bulk milk to predict indicators (1) of diet composition of dairy cows and (2) for the authentication of the cow feeding restrictions included in the specification of 2 PDO cheeses (Cantal and Laguiole) from the mountainous area of Massif Central in France.

\section{MATERIALS AND METHODS}

\section{Milk Sampling and Surveying}

This study was conducted in Massif Central, France, in the territory included in the PDO area of Cantal (about 1,000 producers) and Laguiole (about 70 producers) PDO cheeses. The production area was selected because of the heterogeneity of farming practices and cow feeding strategies of farms included and not included in the PDO production chain. The MIR spectra of bulk milk routinely analyzed for milk payment were collected by the local laboratory (Agrolab) between April 2018 and March 2019. The milk samples originated from dairy farms located in the Cantal and the Aveyron departments. Agrolab's FT-Plus equipment (Foss, Hillerød, Denmark) - working within the MIR region from 5,000 to $1,000 \mathrm{~cm}^{-1}$ — was used for milk infrared spectroscopy analysis, following the International Dairy Federation (2000) standard method. In parallel, the Cantal Conseil Elevage conducted on-farm surveys. This organization routinely collects data about cow diet composition (10 times per year per farm) to assist farmers in optimizing their feeding management. This routine survey service included data about the dairy herd breed, size, and performance, and about cow diet composition ( $\mathrm{kg}$ of DM of each feedstuff/cow $\times$ day). In particular, farmers' declarations of the amounts of hay, grass silage, haylage, maize silage, and concentrates fed to dairy cows' were collected. The DM content of silage was determined on the basis of the analysis of chemical composition and nutritive value available on the farm. Pasture intake was estimated by the difference between the potential intake capacity of the herd at the survey time and the encumbrance provided by the other feedstuffs fed to the herd, following the procedure proposed by Coppa et al. (2012). Potential intake capacity was estimated according to the herd characteristics (milk yield, breed, lactation stage, and so on), as detailed in the INRA (2018). Total DMI was calculated as the sum of the DMI of the various feedstuffs composing the diet. Total DMI data were checked for outliers by removing values considered as nonphysiological (average daily DMI of the herd $<13$ or $>27 \mathrm{~kg}$ of $\mathrm{DM} / \mathrm{cow}$ ). To be more conservative, aiming to achieve the most rigorous reference survey data, surveys in which the values of DMI were considered to be inconsistent with the average milk yield of the herd, breed, and feeding system, and outlier surveys, and their corresponding samples, according to the INRA (2018), were also discarded. Approximately $10 \%$ of the survey data were removed. The survey data were associated with the spectra of 
Table 1. Herd characteristics, performance, and cow diet composition corresponding to milk samples within the calibration and validation sets ${ }^{1}$

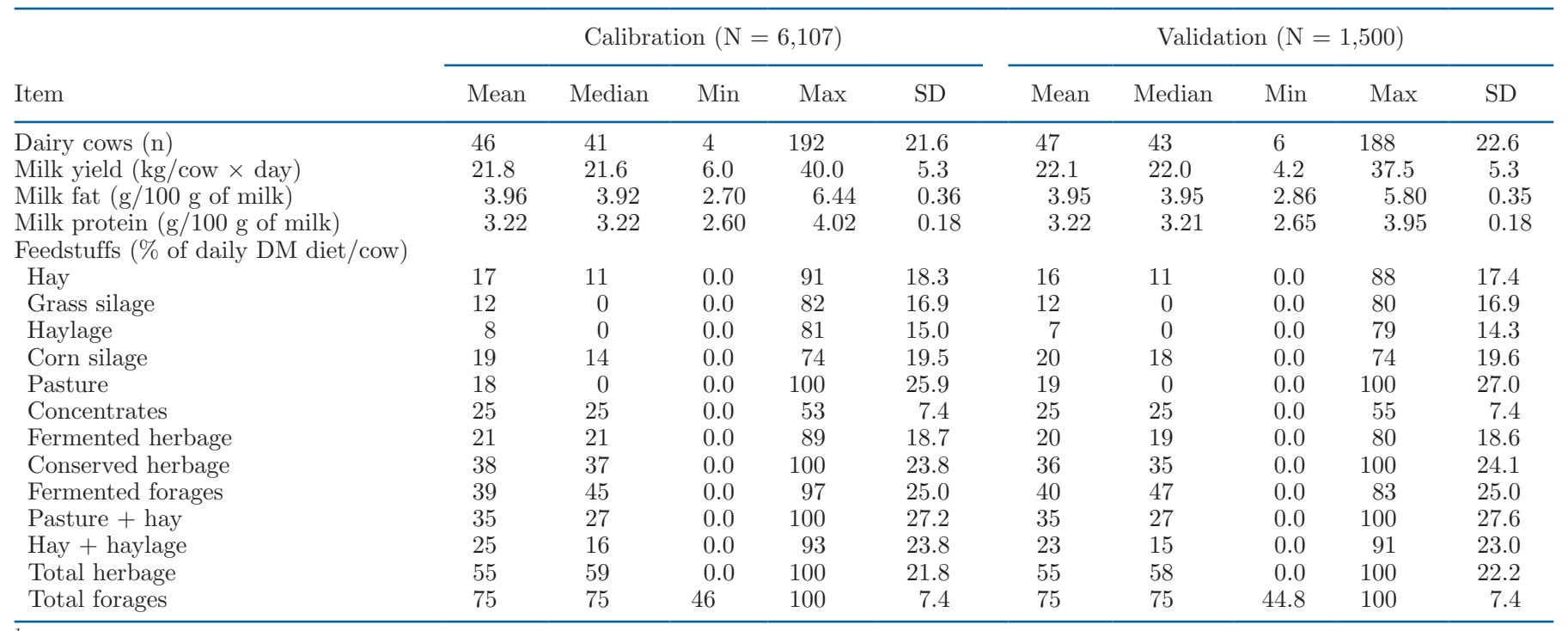

${ }^{1} \mathrm{~N}=$ number of milk samples; $\mathrm{n}=$ number of cows; Min = minimum; Max $=$ maximum.

the bulk milk of each surveyed farm analyzed within a 3-d maximum interval from the survey date. In total, 7,607 bulk milk spectra from 1,355 farms and their corresponding surveys composed the data set. After elimination of the outliers, the data set was composed of an average of 5.6 spectra and associated surveys per farm (range: 1-10), balanced among seasons. Herd characteristics, performance, and cow diet composition corresponding to the samples included in the data set are given in Table 1.

\section{Milk Grouping Based on PDO Cheese Specifications}

The specifications of both Cantal and Laguiole PDO cheeses imposes a minimum of $120 \mathrm{~d}$ of grazing per year, during which the pasture proportion of the cow's diet has to reach minimum proportions, as well as access to grassland-derived forage all year round. The Cantal PDO cheese specifications limit the use of corn silage, and impose minimum amounts of hay out of the grazing season, whereas the Laguiole PDO cheese specifications ban all forms of fermented forage. The specifications of both PDO cheeses limit the amount of concentrate in the cow's diet as well. Several recommendations for the PDO cheese specification are expressed as the proportion of total forage DMI instead of the total DMI, and the concentrate amount is expressed as the maximum total amount/cow $\times$ year. To adapt those parameters and thresholds into proportions of the total intake (as found in the survey data), the average daily DMI/cow for the PDO farms issued from the survey was used as the reference: $19.7 \mathrm{~kg}$ of $\mathrm{DM} /$ cow $\times$ day for both
Cantal and Laguiole cheese. According to the current control methods applied by the PDO cheese to check the concentrate amounts, the total annual concentrate intake/cow $(1,800 \mathrm{~kg}$ of fresh matter) was divided by the standard lactation duration $(305 \mathrm{~d})$. This results in an average daily intake of concentrate of $5.5 \mathrm{~kg}$ of DM/ cow. The concentrates and forage proportions on the total daily DMI/cow were thus calculated accordingly. The details of the criteria and the thresholds for both Cantal and Laguiole PDO cheeses are given in Table 2. Aiming to authenticate the feeding restrictions included in the specifications of the Cantal and Laguiole PDO cheeses, the threshold included in the specification of each feedstuff, as calculated on \% daily total DMI, was used as the criterion for grouping the milk samples. Samples were assigned to 2 groups for each criterion according to the proportion of the feedstuff to which the criterion was referred as $<$ or $\geq$ than the threshold reported in Table 2. Aiming to characterize the feeding system as a whole, overcoming the single feedstuff approach, samples were also grouped according to the simultaneous respect of all (or none) of the threshold criteria of each of the PDO specifications. The characteristics of each group are reported in Tables 3 for Cantal PDO cheese and in Tables 4 for Laguiole PDO cheese.

\section{Statistical Analysis}

For both the prediction of indicators of the feedstuff proportion in the cow diet and of the authentication of the cow feeding restrictions included in the cheese 
Table 2. Feeding recommendation criteria and relative thresholds given in the specification of the Cantal and Laguiole Protected Designation of Origin (PDO) cheeses

\begin{tabular}{lcc}
\hline & \multicolumn{2}{c}{ PDO cheese (\%) } \\
\cline { 2 - 3 } Feedstuffs proportion on herd & Cantal & Laguiole \\
DMI/cow $\times$ day & $>50$ & $>57$ \\
\hline Pasture & & $<28$ \\
Concentrates & $>25$ & $>72$ \\
Pasture + hay & $<30$ & 0 \\
Corn silage & $>50$ & $>72$ \\
Total herbage & - & 0 \\
Fermented herbage & - & 0 \\
Fermented forages & & \\
\hline
\end{tabular}

${ }^{1}$ During at least 120 grazing $\mathrm{d} / \mathrm{yr}$.

specifications, the original data set was divided into a calibration ( $\mathrm{n}=6,107$ from 1,079 farms) and a validation set $(\mathrm{n}=1,500$ from 276 farms). The samples in the calibration and validation sets were selected by the Kennard-Stone algorithm (Kennard and Stone, 1969) applied to spectral data to sample representative sets for both calibration and validation. To make the calibration and validation data sets completely independent, all the milk samples taken from the same farm were included in either the calibration set or the validation set, but not both. The WinISI II Project Manager software, version 1.50 (Infrasoft International, State College, PA) was used for the statistical models.

The calibration of the proportions of the different feedstuffs in the cows' diets was calculated with modified partial least square regressions (Shenk and Westerhaus, 1995). Several spectral correction procedures and mathematical treatments were tested on both the full spectrum or on different wavelength selections. However, the best performing predictions were obtained on the raw spectra, without any correction or mathematical treatment, using only on the segments between 2,989 and $2,561 \mathrm{~cm}^{-1}$, between 1,809 and $1,712 \mathrm{~cm}^{-1}$, and between 1,600 and $926 \mathrm{~cm}^{-1}$, according to Maurice Van Eijndhoven et al. (2013). Thus, only the best performing models were reported. A 16 latent variables calculation was set for each regression, and critical values for Student's $t$-test of $t=2.5$ were adopted to remove any calibration outliers. Two elimination passes during the full cross-validation (6 cross-validation groups) were performed. The maximal number of outliers allowed was $5 \%$ of total number of samples (minimum 67 spectra and maximum 290 spectra discarded). The statistics used to evaluate the calibration models were as follows: the standard error of cross-validation, the coefficient of determination for cross-validation $\left(\mathbf{R}^{2} \mathbf{C V}\right)$, the coefficient of determination in external validation $\left(\mathbf{R}^{2} \mathbf{V}\right)$, the standard error of prediction (SEP), the slope, the bias, and the standard error of the prediction corrected by the bias (SEPC) of the validation set, and the ratio of the standard deviation of the reference data to the standard error of cross-validation (RPD).

Partial least squares discriminant analysis was performed to authenticate the cow feeding restrictions included in the specification of PDO cheeses by applying a full cross-validation (6 cross-validation groups) and an external validation. The characteristics of the groups used for calibration and validation are reported in Tables 3 for the Cantal PDO cheese, and Tables 4 for the Laguiole PDO cheese. According to Fawcett (2006), the sensitivity (calculated as the true-positive rate), specificity (calculated as the true-negative rate), precision (calculated as the true positives over the true + false positives), and accuracy (calculated as the ratio between the true positives + the true negatives and the total samples) were used to evaluate the discriminant model validations. Accordingly, in the current study, the sensitivity and the specificity express the error rate within a group to be discriminated (the adherence or not to a criterion, respectively), whereas the precision expresses the capability of the model to detect the samples, respecting a criterion over all samples, and the accuracy expresses the reliability of the model.

\section{RESULTS}

\section{Variability in Farming Practices}

The average herd size in the validation and calibration data sets was 46 dairy cows. The average daily milk yield was $22 \mathrm{~kg} / \mathrm{cow}$, and milk fat and protein contents were 3.96 and $3.22 \mathrm{~g} / \mathrm{kg}$ of milk, respectively (Table 1). The herd size, milk yield, and composition highlighted large diversity in farming systems, from small-size herds of double-purpose local breeds typical of family farming under extensive farming systems in mountainous areas to large-size herds of specialized high-yielding dairy breeds characteristic of intensive dairy farming systems. The diet composition ranged from corn silage- or grass silage-based diets to haybased diets or full grazing without concentrate supplementation. The average pasture, hay, grass silage, corn silage, and concentrate proportions were $18,17,12,8$, 19 , and $25 \%$ for daily DMI (Table 1 ). The apparent low yearly averaged proportion of the various feedstuff is in coherence with the seasonal adaptation of diets to the forage availability. This seasonality emerged in particular from the differences between means and medians for hay, grass silage, haylage, and pasture. Taking the pasture proportion as an example, not all farms grazed their herds and pasture was not available all year round for grazing herds (resulting in a median equal to zero). The grazing period varied widely due to the heterogeneity of farming management and the climate in the 


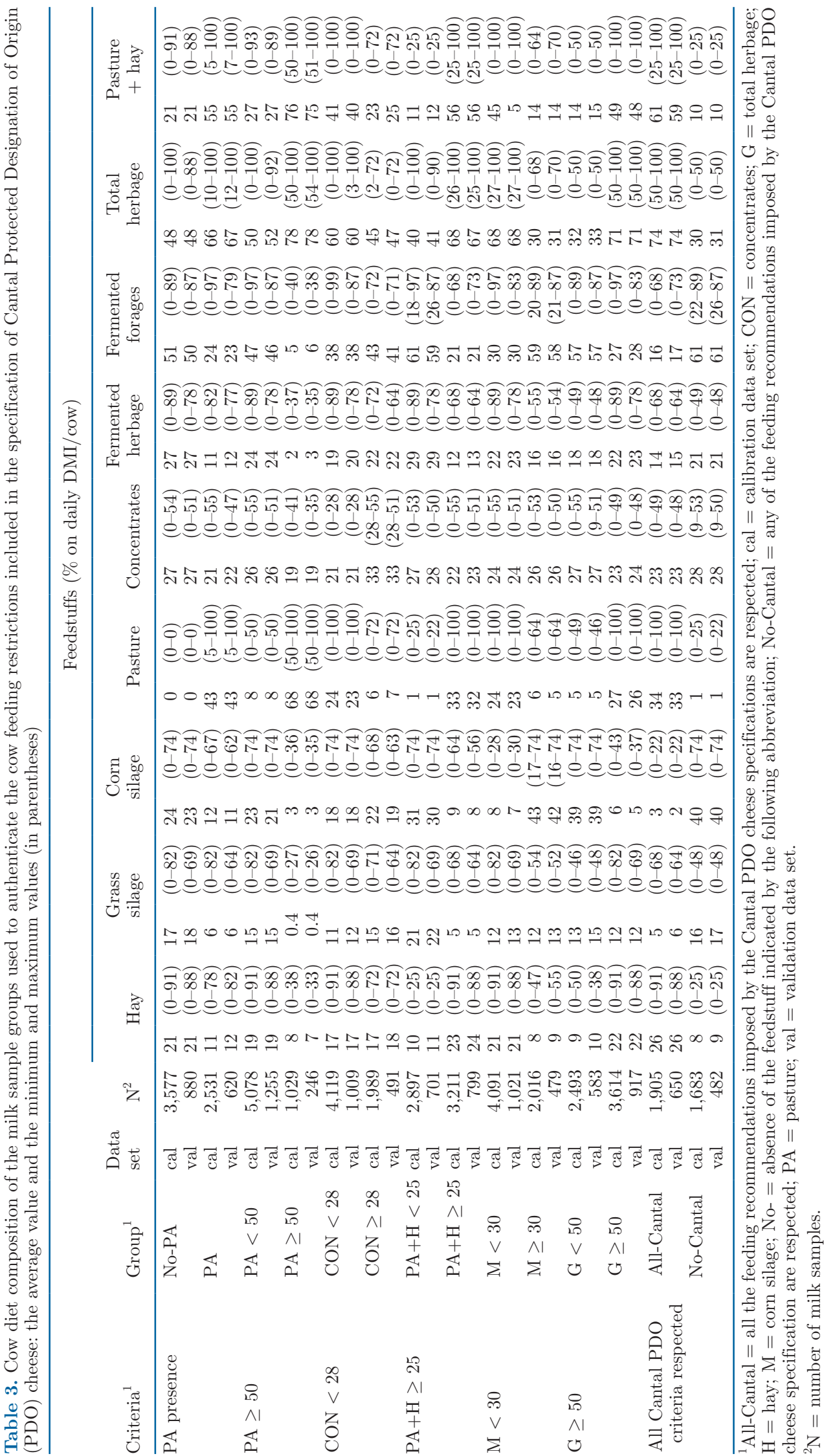




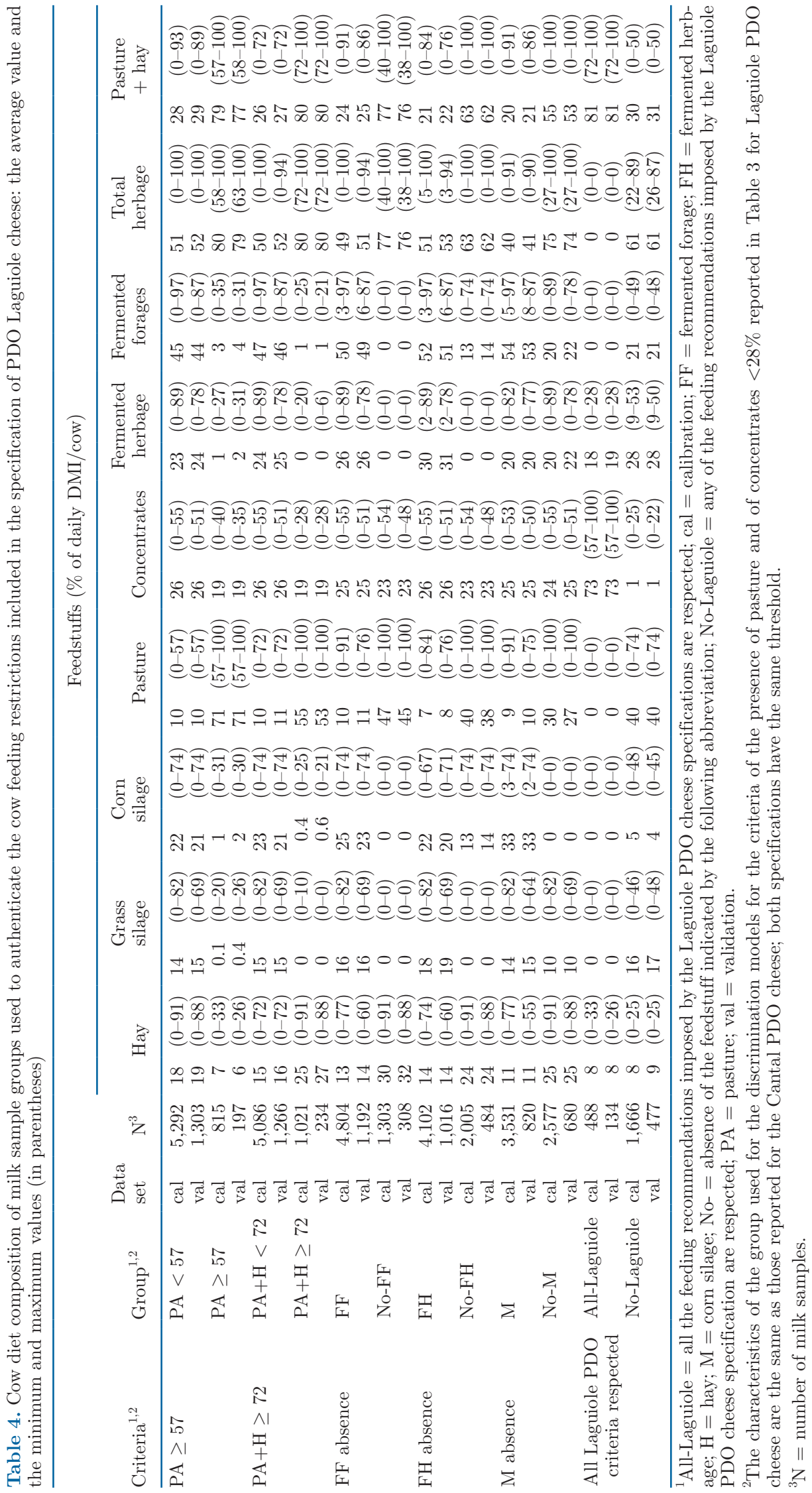


studied area. At the upper altitude of Massif Central, the grazing season started in May and ended in September. However, in the lower altitude part of the studied region (especially in its south), grazing herds were surveyed from February to December, but there was an interruption during the driest months of the summer. This extreme variability validated the selection of the studied territory to explore a wide range of management practices and, consequently, the cows' diet composition. Tables 3 and 4 give the descriptive statistics of cow diet composition within each group used for the authentication of the feeding restrictions included in the specification of PDO cheeses for the calibration and validation sets. The descriptive statistics for each milk sample group were similar between the calibration and validation sets. The pasture group was characterized on average by $43 \%$ of pasture in the cows' diet DMI, and by approximately $12 \%$ of hay and corn silage, and $6 \%$ of hay and haylage. The absence of pasture group had about twice the proportion of hay, haylage, and corn silage and 3 times the proportion of grass silage than the pasture group, but a slightly higher concentrate proportion ( 27 vs. $22 \%$, respectively). The pasture $\geq 50 \%$ and pasture $\geq 57 \%$ groups had an average pasture proportion of approximately 67 and $71 \%$, respectively, whereas the average pasture proportion was lower than $10 \%$ in the pasture $<50 \%$ and pasture $<57 \%$ groups. They showed similar proportions of hay, grass silage, haylage, corn silage, and concentrates $(19,15,9,21$, and $26 \%$, respectively). Concerning the concentrate criterion, out of the expected differences in concentrate proportions ( 21 vs. $33 \%$ for the concentrate $<28 \%$ and concentrate $\geq 28 \%$ groups, respectively), the concentrate $<28 \%$ group showed on average a higher pasture proportion compared with the concentrate $\geq 28 \%$ group (24 vs 6\%, respectively), but the average proportion in the cows' diet of the other forages were similar. When comparing the pasture + hay $\geq 72 \%$ and pasture + hay $<72 \%$ groups, this last compensated for the lower pasture and hay proportions (10 vs. $55 \%$ and 16 vs. $25 \%$, respectively) with $15 \%$ grass silage, $10 \%$ haylage, $22 \%$ corn silage, and $7 \%$ more concentrates. Similar trends were observed for the pasture + hay $\geq 25 \%$ and pasture + hay $<25 \%$ groups. When comparing the groups with and without fermented forages and with and without fermented herbage, the absence of fermented forages resulted in 10 to $20 \%$ and a 40 to $45 \%$ increases in hay and pasture proportions in the cows' diets, respectively (and a 13\% increase in corn silage for the absence of fermented herbage group). The corn silage $<30 \%$ group had $35 \%$ less corn silage on average than the corn silage $\geq 30 \%$ group, and it was replaced with $13 \%$ more hay and approximately $20 \%$ more pasture in the cows' diet. The total herbage $<50 \%$ group showed approximately
$13 \%$ less hay, $20 \%$ less pasture, and 35\% more corn silage in the cows' diet compared with the total herbage $\geq 50 \%$ group.

The diet of the herds respecting simultaneously all the threshold criteria of each of the Cantal PDO specifications was characterized on average by $33 \%$ of pasture, $16 \%$ of hay, $23 \%$ of concentrates, and less than $5 \%$ of grass silage and corn silage. In the group respecting simultaneously none of the threshold criteria of each of the Cantal PDO specifications, pasture was almost absent in the cows' diet, corn silage made up approximately $40 \%$, hay was decreased to less than $10 \%$, and grass silage increased to approximately $16 \%$. According to the stronger limitations on cow feeding imposed by the Laguiole PDO cheese specification compared with Cantal PDO cheese, the forages in the cows' diet of the group respecting simultaneously all the threshold criteria of each of the Laguiole PDO specifications were pasture and hay only (pasture + hay approximately $81 \% ; 18 \%$ of concentrates). The cows' diet in the group respecting simultaneously none of the threshold criteria of each of the Laguiole PDO specifications was based mainly on corn silage (approximately 40\%), associated with $16 \%$ of grass silage, $5 \%$ haylage, and $28 \%$ concentrates.

\section{Prediction of Cow Diet Composition}

The calibration and validation statistics of the prediction equations for the indicators of the proportion of different feedstuffs in the cows' diets are given in Table 5. The proportion of pasture in the dairy herds' diets was predicted by MIR, with $\mathrm{R}^{2} \mathrm{~V}=0.81, \mathrm{RPD}=2.17$ and SEP $=11.7 \% \mathrm{DM}$ in the cows' diets. The pasture + hay proportion was predicted with $\mathrm{R}^{2} \mathrm{~V}=0.74$, RPD $=1.89$, and SEP $=13.6 \% \mathrm{DM}$ in the cows' diets, but the model was less precise than the pasture proportion alone. This was probably because of the poor prediction of the hay proportion $\left(\mathrm{R}^{2} \mathrm{~V}=0.42, \mathrm{RPD}=1.23\right.$, $\mathrm{SEP}=13.1 \% \mathrm{DM}$ in the cows' diets). Predictions for the corn silage, conserved herbage, fermented forage, and total herbage proportions in the cows' diets showed $\mathrm{R}^{2} \mathrm{~V}>0.61$, RPD $>1.59$, and SEP $<14.8 \%$ DM. Out of the abovementioned hay proportions, predictions with $\mathrm{R}^{2} \mathrm{~V}<0.5$ were found for the grass silage, concentrates, fermented herbage, hay + haylage, and total forage proportions.

\section{Authentication of Cow Feeding Recommendations Included in the PDO Specifications}

The calibration and validation results of the discriminant analysis performed to develop indicators to authenticate the restrictions in cow feeding included in 
Table 5. Results of the mid-infrared prediction model for cow diet composition in the calibration and validation sets

\begin{tabular}{|c|c|c|c|c|c|c|c|c|c|}
\hline $\begin{array}{l}\text { Feedstuffs } \\
\text { (\% DM on total diet) }\end{array}$ & \multicolumn{4}{|c|}{ Calibration $^{1}$} & \multicolumn{5}{|c|}{ Validation $(\mathrm{n}=1,500)^{2}$} \\
\hline Grass silage & 5,853 & 11.7 & 0.29 & 1.19 & 15.1 & 3.31 & 14.7 & 1.13 & 0.26 \\
\hline Corn silage & 6,040 & 11.9 & 0.62 & 1.61 & 12.2 & 0.30 & 12.2 & 0.98 & 0.61 \\
\hline Pasture & 5,941 & 11.7 & 0.79 & 2.17 & 11.7 & -0.46 & 11.7 & 1.01 & 0.81 \\
\hline Concentrates & 5,894 & 5.6 & 0.30 & 1.19 & 6.2 & 0.32 & 6.2 & 0.99 & 0.26 \\
\hline Fermented forages & 5,943 & 14.4 & 0.66 & 1.85 & 14.0 & 0.76 & 13.9 & 0.97 & 0.67 \\
\hline Pasture + hay & 5,941 & 14.2 & 0.72 & 1.89 & 13.6 & -0.84 & 13.6 & 0.99 & 0.74 \\
\hline Hay + haylage & 5,980 & 16.2 & 0.51 & 1.43 & 16.7 & -0.20 & 16.7 & 0.93 & 0.46 \\
\hline Total herbage & 6,011 & 12.1 & 0.68 & 1.78 & 12.3 & -0.34 & 12.3 & 0.98 & 0.68 \\
\hline Total forages & 5,880 & 5.5 & 0.33 & 1.22 & 6.1 & -0.18 & 6.1 & 0.98 & 0.29 \\
\hline
\end{tabular}

${ }^{1} \mathrm{~N}=$ number of samples included in the calibration set; SECV $=$ standard error in cross-validation; $\mathrm{R}^{2} \mathrm{CV}=$ coefficient of determination in cross-validation; $\mathrm{RPD}=$ the ratio of the standard deviation of the reference data to the SECV.

${ }^{2} \mathrm{SEP}=$ standard error of prediction in external validation; $\mathrm{SEPC}=\mathrm{SEP}$ corrected for the bias; $\mathrm{R}^{2} \mathrm{~V}=$ coefficient of determination in external validation.

the specification of Cantal and Laguiole PDO cheeses are reported in Table 6 and Table 7 , respectively.

The performance of the discriminant analysis was similar in the calibration and external validation sets; thus, only the validation results are discussed. Concerning the discrimination model for a single criterion of the PDO specifications, the models for pasture presence, pasture $\geq 50 \%$, and pasture $\geq 57 \%$ in the cows' diets achieved an accuracy and specificity $\geq 90 \%$. Sensitivity and precision $\geq 85 \%$ were also observed for the pasture presence discrimination model. However, when comparing the pasture presence model to the pasture $\geq 50$ and pasture $\geq 57$ models, the precision and especially the sensitivity decreased when increasing the pasture proportion threshold from 0 to 50 and $57 \%$. Pasture + hay $\geq 72 \%$ showed a precision $\geq 80 \%$, and a sensitivity $<80 \%$, but the accuracy was $\geq 85 \%$ and the specificity was $\geq 90 \%$. Similarly, the sensitivity and precision were $<80 \%$, and the accuracy was $\geq 85 \%$, whereas the specificity was $\geq 90 \%$ for the model with an absence of fermented forage in the cows' diets. All of the statistics for the discriminant model for herbage $\geq 50 \%$ in the cows' diets were $\geq 85 \%$, except for the specificity ( $\geq 80 \%$ ). The sensitivity or precision were $\geq 85 \%$ for pasture + hay $\geq 25 \%$, the absence of fermented herbage, absence of corn silage, and corn silage $\leq 30 \%$ in the cows' diets, but for all of these models, the accuracy was $\geq 80 \%$.

Accuracy, specificity, sensitivity, and precision $\geq 90 \%$ were observed for the discrimination models based on the simultaneous respect of all of the criteria included in the specifications for both the Cantal and Laguiole PDO cheeses, but the model for the Laguiole PDO cheese performed better (accuracy, specificity, sensitivity, and precision $>97 \%$ ).
The main wavelengths implicated in discriminating between the different groups used to develop indicators to authenticate the cow feeding restrictions included in the specification are given in Figure 1 for pasture presence, pasture $\geq 50$, pasture $\geq 57$, concentrate $<28$, and corn silage and fermented herbage absence in the cows' diet. The spectral regions showing the most important differences between the groups of specification criteria were between 2,985 and $2,830 \mathrm{~cm}^{-1}$, between 1,770 and $1,730 \mathrm{~cm}^{-1}$, and to a lesser extent, between 1,581 and $1,504 \mathrm{~cm}^{-1}$, between 1,480 and $925 \mathrm{~cm}^{-1}$, whatever the criterion considered. The extent of the differences in wavelength absorbance was larger when all of the specification criteria were simultaneously respected instead of just a single criterion. Among the single criteria, the absorbance differences between groups were larger for the criteria based on pasture or corn silage presence or proportion compared with fermented herbage presence or concentrate proportions in the cows' diets.

\section{DISCUSSION}

\section{Prediction of Cow Diet Composition}

To the best of our knowledge, this is the first study to propose the use of MIR spectra obtained from bulk milk from commercial farms to predict indicators of cow diet composition for authentication purposes of PDO cheese specifications. Our models predict the proportion of pasture, pasture + hay, corn silage, conserved herbage, fermented forage, and total herbage in the cows' diets with $\mathrm{R}^{2} \mathrm{~V}>0.6$ and SEP $<15 \%$ for the DM diet. Working on individual cow milks on experimental farms, Klaffenböck et al. (2017) found 
Coppa et al.: MILK AUTHENTICATION BY MID-INFRARED SPECTROSCOPY
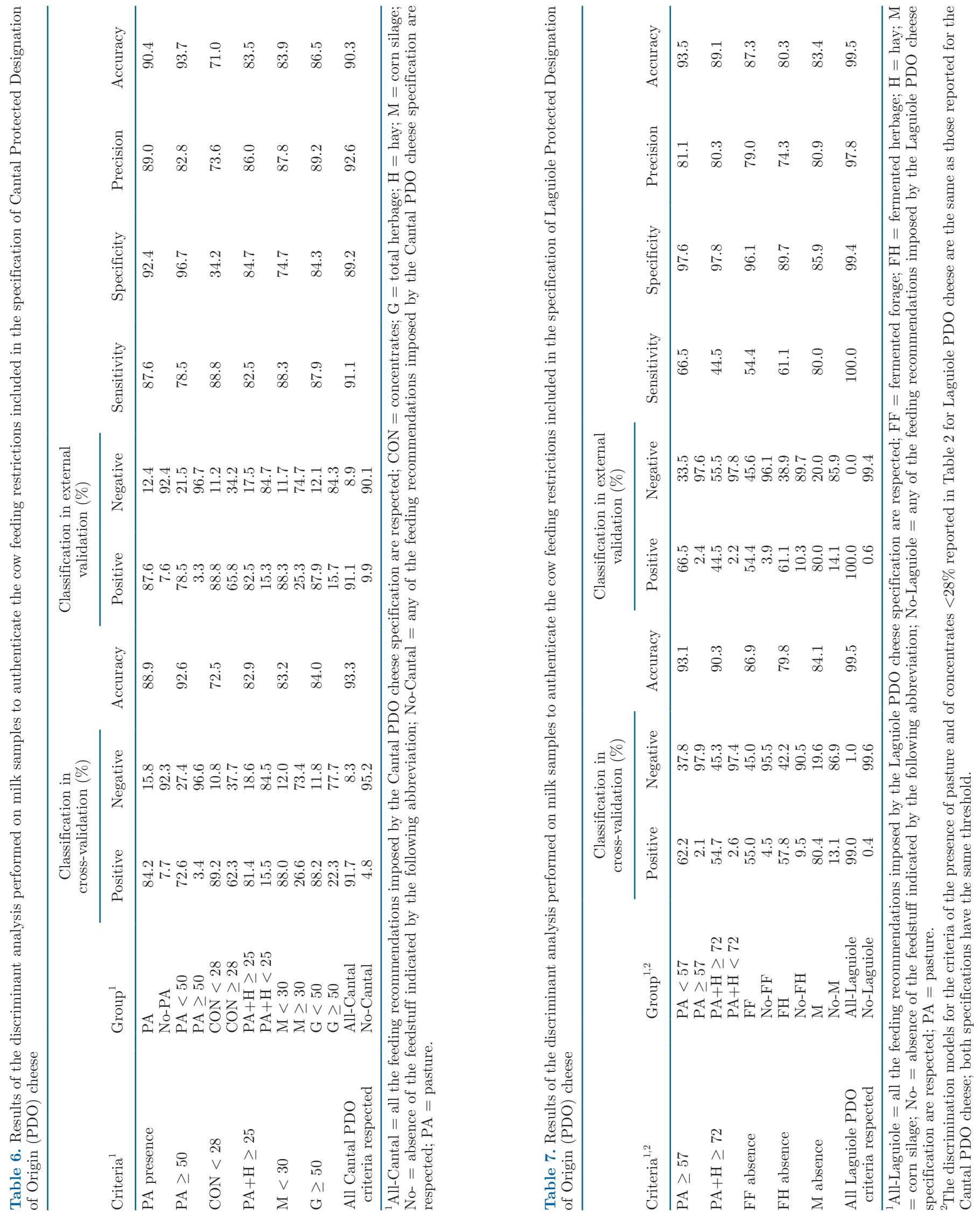

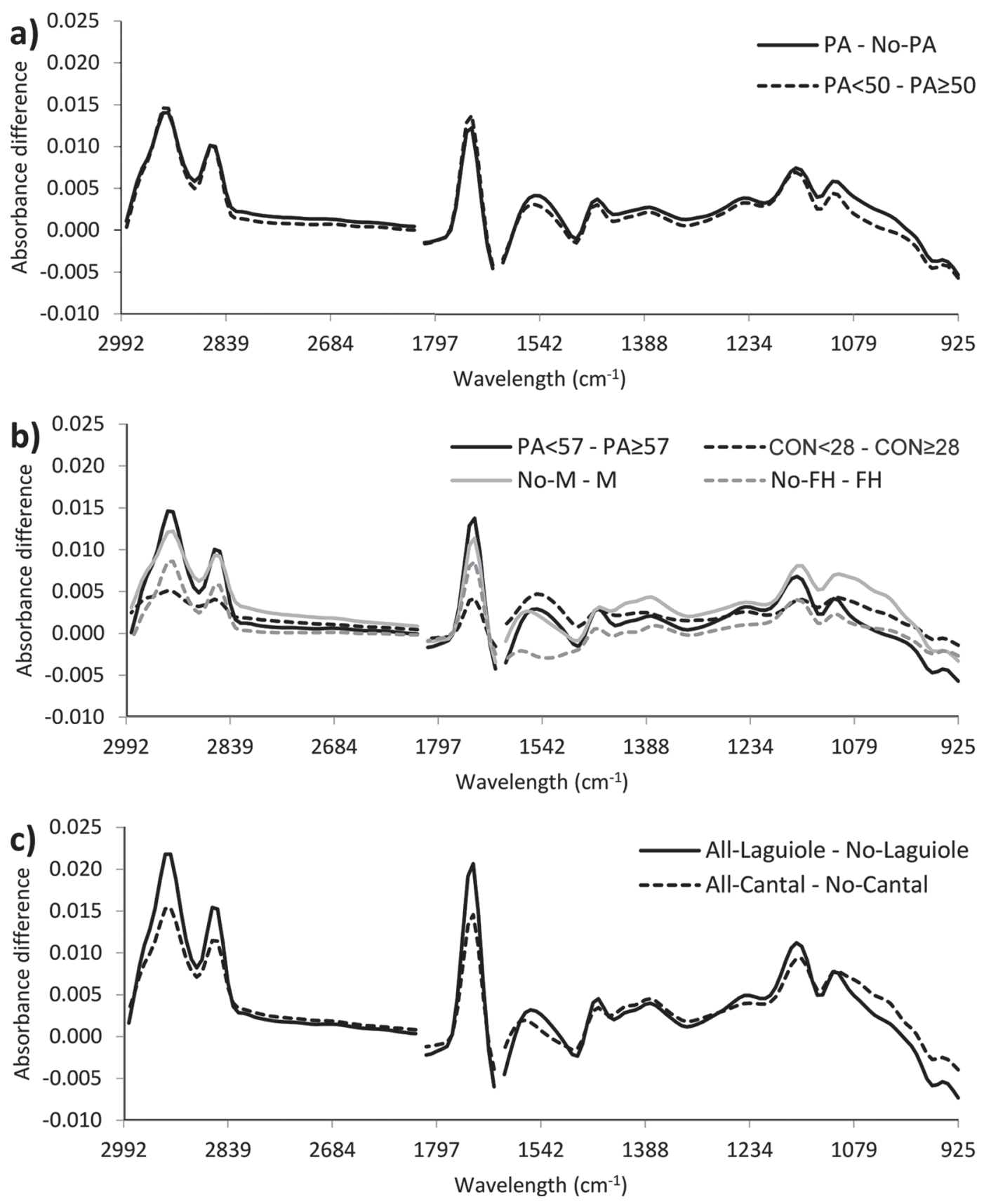

Figure 1. Differences between the average spectra of the groups used to authenticate the cow feeding restrictions included in the specification for the criteria: (a) pasture (PA) presence (PA vs. No-PA), and PA $>50 \%$ of the daily DM diet (PA $<50$ vs. PA $>50)$, for Cantal Protected Designation of Origin (PDO) cheese; (b) PA $\geq 57 \%$ of the daily DM diet (PA $<57$ vs. PA $\geq 57$ ), concentrates $(\mathrm{CON})<28 \%$ of the daily DM diet $(\mathrm{CON}<28$ vs. $\mathrm{CON} \geq 28)$, corn silage $(\mathrm{M})$ absence (No-M vs. M), and fermented herbage absence (No-FH vs. FH) for Laguiole PDO cheese; and (c) all the Cantal PDO cheese specification criteria for feeding restrictions are respected (All-Cantal vs. No-Cantal), and all the Laguiole PDO cheese specification criteria for feeding restrictions are respected (All-Laguiole vs. No-Laguiole). No- = absence of the feedstuff indicated by the following abbreviation.

less reliable predictions of cow diet composition using data from 7 different experiments. The use of a few contrasted diets from homogeneous groups of animals and the use of individual cows' milk, instead of bulk milk, could be the reason for the lower performances found by Klaffenböck et al. (2017). The SEP of our models (between 10 and 15\%) had a similar extent to those previously reported for the prediction of various analytically determined milk constituents, such as n-3 FA, CLA, branched-chain FA, or PUFA (Soyeurt et al., 
2011; Coppa et al., 2017), or calcium and other minerals (Soyeurt et al., 2009; Toffanin et al., 2015). When milk spectra are used for an indirect estimation of milk properties that are supposed to be related to milk composition, the prediction performances $\left(\mathrm{R}^{2} \mathrm{~V}\right.$ and SEP) were similar to those we found. This is the case for milk color (McDermott et al., 2016), related to milk carotenoid and vitamin content (Nozière et al., 2006); for cheese-making properties (Sanchez et al., 2018), related to protein, casein content, casein type, and so on (Fox, 1999); and for methane emissions, related to milk FA composition (Dehareng et al., 2012; Vanlierde et al., 2018). The main wavelengths associated with differences in feedstuff proportions in our models were (1) those between 900 to $1,500 \mathrm{~cm}^{-1}$, which are related to $\mathrm{C}-\mathrm{H}$ bending and $\mathrm{C}-\mathrm{O}$ stretching; (2) those between 1,550 to $1,570 \mathrm{~cm}^{-1}$, which are related to protein absorption (De Marchi et al., 2013); and (3) those between 2,855 to $2,928 \mathrm{~cm}^{-1}$ and 1,805 to $1,736 \mathrm{~cm}^{-1}$, which are related to lipid absorption (De Marchi et al., 2011; Capuano et al., 2014). This finding seems to confirm that MIR is able to detect differences in milk and in particular in milk fat composition induced by cow diet composition. The cow feeding strategy is known to be the most powerful factor in changing milk fat composition (Coppa et al., 2019; Prache et al., 2020).

Furthermore, when comparing the SEP of our model to those of analytically determined constituents, the incertitude of the reference method must be taken into account. Milk analytical methods should be more accurate and precise than on-farm surveys. On-farm estimations of the intake of different feedstuffs can be exposed to imprecisions. In example, concentrates are not always weighted, but fed by a farmer in a certain volume (i.e., 1 bucketful/cow $\times$ day), hay is given in bales of variable weight, the silage DM content can vary between different series of wrapped bales or from one cut to another within the same silage bank, and so on. Pasture intake estimation errors have even more impact, as the estimation of fresh herbage intake of grazing herds on commercial farms is still an unsolved problem. An estimation error of 10 to $15 \%$ for the DMI on a herd diet of at least a feedstuff can be considered intrinsic in the reference data and is in line with the SEP of our models. Indeed, similar residual errors were observed for the prediction model of cow diet composition based on analytically determined milk constituents when built from on-farm survey data (Coppa et al., 2015a). Both MIR prediction models built either for analytically determined milk constituents or for indirectly estimated indicators with prediction performance comparable to our models were considered suitable for application in genetic selection or in screenings (De Marchi et al., 2014). Thus, the use of our models for authentication purposes is possible, but practical implications for their careful use are required.

\section{Authentication of Cow Feeding Restrictions in PDO Specifications}

Recently, MIR was proposed on milk for the authentication of farming systems (Valenti et al., 2013; Capuano et al., 2014; Bergamaschi et al., 2020). However, it has never been tested for the authentication of the cow feeding restrictions included in the specification of PDO cheeses. Authentication testing on a large number of bulk milk samples collected on commercial farms is novel in our study as well. Our discrimination model showed an accuracy $\geq 90 \%$ for the pasture presence at different proportions in the cows' diets. The capability of MIR to authenticate the presence of fresh herbage in cows' diets was tested on a small number of samples by Capuano et al. (2014), showing a similar sensitivity and a lower specificity $(83 \%)$ in cross-validation. Capuano et al. (2014) highlighted that this classification was largely imputable to the wavelengths related to fat content and composition. This is in agreement with our findings and confirms the dominant role of pasture feeding on FA composition and fat-soluble compounds (Prache et al., 2020). Valenti et al. (2013), when comparing pasture-derived milk to milk issued from the various conserved forage-based diets, observed better discrimination results. However, this research compared contrasted diets $(>65 \%$ of fresh herbage or conserved forage in cows' diets), whereas in our data set, a large number of mixed diets with herbage proportions less than $65 \%$ were included in the data set. Within the discrimination models for different thresholds of pasture proportions in cows' diets, the decrease in the sensitivity and specificity (accompanied by a slight increase in the specificity), observed when increasing from 0 to 50 , and $57 \%$ of the pasture proportion threshold in the cows' diets, appear to agree with the findings of Coppa et al. (2012). Using NIR on bulk milk for cow feeding authentication, the authors showed that in over $70 \%$ of pasture in cows' diets, the variability induced by pasture characteristics (phenological stage, botanical composition, foraging management, selection, and so on; Coppa et al., 2015b) may overcome those induced by the fresh herbage proportion (Renna et al., 2020). The herbage characteristics can generate "background noise" that does not allow us to further improve the classification performances within the pasture group (Coppa et al., 2012). This is in agreement with the similar spectral differences between the absence of pasture group and those of different pasture thresholds in the cow diets we found (Figure 1). Similar consideration can also be made to explain the lower sensitivity of the dis- 
crimination model of pasture + hay $\geq 72 \%$ than that of pasture + hay $\geq 25 \%$. Furthermore, as the specification criteria threshold becomes more restrictive, the range of a specific feedstuff in the group becomes smaller (i.e., pasture between 72 to $100 \%$; concentrate between 0 and $28 \%$ ). At a constant error rate in the reference data within both groups (previously discussed), the probability of an incorrect estimation appears higher in the group with a lower range of feedstuff proportions. Consequently, a higher discrimination error could be found for the small group. Furthermore, the lack of sensitivity (as in the fermented forage absence and fermented herbage absence models) or specificity (as in the concentrate $<28 \%$ ) is not surprising when considering the single feedstuff criteria approach applied. Indeed, on commercial farms, feeding with unfermented herbage or fermented forage and giving more or less than $28 \%$ concentrate or more or less than $30 \%$ corn silage offers a large variety of other feedstuff utilizations. This is clearly shown by the range of variation of the various feedstuffs within the fermented forage, nofermented forage, fermented herbage, and no-fermented herbage, or by the similarity of the average various forage proportions between the $\mathrm{C}<28$ and $\mathrm{C} \geq 28$ groups. These other feedstuff types and proportions can affect milk composition and characteristics equally or even more than the single feedstuff used to fix a threshold (i.e., given a fixed proportion of concentrates, for example, $28 \%$, increasing the pasture proportion by $50 \%$ by decreasing corn silage or vice versa results in very different milk; Couvreur et al., 2006; Coppa et al., 2015a). This hypothesis is also in agreement with the lower spectral differences among groups based on the concentrate threshold or on the absence of fermented herbage compared with the criteria based on the presence or proportions of pasture or corn silage (Figure 1).

When considering all the criteria for feeding restrictions of a PDO cheese specification, a particular feeding and farming system is implemented to match all of the criteria. Indeed, the discrimination performances of the model based on the respect of all the specification criteria yields better performances, with no relevant differences between the sensitivity and specificity. Furthermore, the spectral absorbance differences between the groups in the discriminant analysis were larger (Figure 1). The performance is better as the restrictions in the PDO specifications become more specific. Strong restriction more precisely outline a specific feeding and farming system, as is the case for the Laguiole PDO cheese compared with the Cantal PDO cheese. When comparing the discrimination performances we obtained on the models based on the simultaneous respect of all the PDO cheese feeding restriction criteria, the results are similar to those obtained when discriminating organic and conventional milk (Capuano et al., 2014) or even better than those found comparing traditional and modern farming systems (Bergamaschi et al., 2020).

\section{Practical Implications for Careful Use of the Indicators Predicted by the Models}

Even if both the performance of the prediction of various feedstuffs in the cows' diet and the discrimination model for the authentication of the PDO cheese specification criteria are in line with possible routine use, some precautions are needed. Considering the uncertainty of the reference data and the average model errors, the outputs of both the prediction and discrimination models have to be considered as indicators of the cows' diet composition respecting the PDO specification criteria, rather than an accurate measure. Indeed, the model gives a prediction or a classification of a single sample at a specific moment, but the specification criteria are often expressed on an annual basis. Furthermore, concerning the discrimination model, it is important to remember that the threshold has been calculated by the conversion of the total amount of concentrate per lactation into an average proportion per day, using the average total DMI. This adaptation implies classification incertitude of the samples close to the threshold. Thus, an overview of the classification results of a farm must be performed yearly to correctly interpret the classification results, taking into account the model's error. An overview of the classification of single samples in a given period is also a technical need considering the amount of data per PDO cheese association that can be predicted monthly. For milk payment purposes, milk samples are currently analyzed after each milk tank delivery per farm, resulting in more than 15,000 milk samples per month for the Cantal PDO cheese. Keeping in mind this careful approach, the indicators given by the models can be useful for authentication purposes to screen for respect of the specifications on each farm and to orient the control measures routinely applied by the Cantal and Laguiole PDO Cheese Associations for this purpose. Predictive equations for the indicators of the proportion of the different feedstuffs in the cows' diet could be applied to milk produced out of the studied area, associated or not with a PDO cheese specification, after a minor adaptation of the models. Indeed, integration into the calibration of a sample set (and related reference data) from the enlarged area or farming management context (and consequently a new model validation) has to be preliminary performed. Discrimination models are built on the specifications of the Cantal and Laguiole PDO cheeses. These models could thus be adapted only to other PDO cheeses that 
share the same specification criteria, given the same considerations previously illustrated on model adaptation to new contexts. If the specification of a new PDO cheese includes a criterion or a threshold different from those of the studied PDO cheeses, a dedicated model has to be developed.

\section{CONCLUSIONS}

Our study showed the ability of MIR on bulk milk to predict indicators of the proportion of several of the main feedstuffs in cows' diets with the residual error in line with the limits of the reference data issued through on-farm surveys. Such a model that can give producers useful indicators of cow diet composition is able to strengthen the commitments made with consumers through labeling and specifications. Discriminant models can also provide useful indicators for the respect of each criterion or of all the criteria simultaneously for the feeding restrictions included in the specifications. Discriminant models can be a useful tool for the Cantal and Laguiole PDO production chain to target their routine internal controls, potentially becoming a new tool for precision farming. However, careful use of the indicators, considering a yearly overview of the classification results of a farm, is needed to correctly interpret the classification results. Further studies would be useful to consolidate the prediction and discrimination models, including several years of observations and to adapt the models to other PDO cheese or dairy product specifications.

\section{ACKNOWLEDGMENTS}

This work was supported and funded by the Centre National Interprofessionnel de l'Economie Laitière (CNIEL, Paris, France) through the "Alimir" project. We also thank the Comité Interprofessionnel des fromages du Cantal (CIF, Aurillac, France), the Laguiole PDO Cheese Association (Laguiole, France), and all the dairy farms for their involvement and agreement to participate in the project. The authors also thank the INRAE technical staff (Saint Genes Champanelle, France), particularly Y. Goudron for the informatics support and F. Picard for the support in the statistical treatment. The authors did not have any conflict of interest.

\section{REFERENCES}

Andueza, D., C. Agabriel, I. Constant, A. Lucas, and B. Martin. 2013. Using visible or near infrared spectroscopy (NIRS) on cheese to authenticate cow feeding regimes. Food Chem. 141:209-214. https: //doi.org/10.1016/j.foodchem.2013.02.086.
Auerswald, K., R. Schäufele, and G. Bellof. 2015. Routing of fatty acids from fresh grass to milk restricts the validation of feeding information obtained by measuring $13 \mathrm{C}$ in milk. J. Agric. Food Chem. 63:10500-10507. https://doi.org/10.1021/acs.jafc.5b03646.

Bergamaschi, M., C. Cipolat-Gotet, A. Cecchinato, S. Schiavon, and G. Bittante. 2020. Chemometric authentication of farming systems of origin of food (milk and ripened cheese) using infrared spectra, fatty acid profiles, flavor fingerprints, and sensory descriptions. Food Chem. 305:125480. https://doi.org/10.1016/j.foodchem.2019 .125480 .

Cabiddu, A., C. Delgadillo-Puga, M. Decandia, and G. Molle. 2019. Extensive ruminant production systems and milk quality with emphasis on unsaturated fatty acids, volatile compounds, antioxidant protection degree and phenol content. Animals (Basel) 9:771. https://doi.org/10.3390/ani9100771.

Capuano, E., J. Rademaker, H. van den Bijgaart, and S. M. van Ruth. 2014. Verification of fresh grass feeding, pasture grazing and organic farming by FTIR spectroscopy analysis of bovine milk. Food Res. Int. 60:59-65. https://doi.org/10.1016/j.foodres.2013.12.024.

Coppa, M., C. Chassaing, A. Ferlay, C. Agabriel, C. Laurent, G. Borreani, R. Barcarolo, T. Baars, D. Kusche, O. M. Harstad, J. Verbič, J. Golecký, C. Delavaud, Y. Chilliard, and B. Martin. 2015a. Potential of milk fatty acid composition to predict diet composition and authenticate feeding systems and altitude origin of European bulk milk. J. Dairy Sci. 98:1539-1551. https://doi.org/10.3168/ jds.2014-8794.

Coppa, M., C. Chassaing, C. Sibra, A. Cornu, J. Verbič, J. Golecký, E. Engel, J. Ratel, A. Boudon, A. Ferlay, and B. Martin. 2019. Forage system is the key driver of mountain milk specificity. J. Dairy Sci. 102:10483-10499. https://doi.org/10.3168/jds.2019-16726.

Coppa, M., A. Farruggia, P. Ravaglia, D. Pomiès, G. Borreani, A. Le Morvan, and A. Ferlay. 2015b. Frequent moving of grazing dairy cows to new paddocks increases the variability of milk fatty acid composition. Animal 9:604-613. https://doi.org/10.1017/ S1751731114003000.

Coppa, M., B. Martin, C. Agabriel, C. Chassaing, C. Sibra, I. Constant, B. Graulet, and D. Andueza. 2012. Authentication of cow feeding and geographic origin on milk using visible and near-infrared spectroscopy. J. Dairy Sci. 95:5544-5551. https://doi.org/10 $.3168 /$ jds.2011-5272.

Coppa, M., A. Revello-Chion, D. Giaccone, E. Tabacco, and G. Borreani. 2017. Could predicting fatty acid profile by mid-infrared reflectance spectroscopy be used as a method to increase the value added by milk production chains? J. Dairy Sci. 100:8705-8721. https://doi.org/10.3168/jds.2016-12382.

Couvreur, S., C. Hurtaud, C. Lopez, L. Delaby, and J. L. Peyraud. 2006. The linear relationship between the proportion of fresh grass in the cow diet, milk fatty acid composition, and butter properties. J. Dairy Sci. 89:1956-1969. https://doi.org/10.3168/jds.S0022 -0302(06)72263-9.

De Marchi, M., M. Penasa, A. Cecchinato, M. Mele, P. Secchiari, and G. Bittante. 2011. Effectiveness of mid-infrared spectroscopy to predict fatty acid composition of Brown Swiss bovine milk. Animal 5:1653-1658. https://doi .org/10. 1017/ S1751731111000747.

De Marchi, M., V. Toffanin, M. Cassandro, and M. Penasa. 2013. Prediction of coagulating and noncoagulating milk samples using mid-infrared spectroscopy. J. Dairy Sci. 96:4707-4715. https://doi .org/10.3168/jds.2012-6506.

De Marchi, M., V. Toffanin, M. Cassandro, and M. Penasa. 2014. Invited review: Mid-infrared spectroscopy as phenotyping tool for milk traits. J. Dairy Sci. 97:1171-1186. https://doi.org/10.3168/ jds.2013-6799.

Dehareng, F., C. Delfosse, E. Froidmont, H. Soyeurt, C. Martin, N. Gengler, A. Vanlierde, and P. Dardenne. 2012. Potential use of milk mid-infrared spectra to predict individual methane emission of dairy cows. Animal 6:1694-1701. https://doi.org/10.1017/ S1751731112000456.

Fawcett, T. 2006. An introduction to ROC analysis. Pattern Recognit. Lett. 27:861-874. https://doi.org/10.1016/j.patrec.2005.10.010. 
Fox, P. F. 1999. Cheese: Chemistry, Physics and Microbiology. Vol. 1, General Aspects. 2nd ed. P. F. Fox, ed. Aspen Publishers Inc., Gaithersburg, MD

Giaccone, D., A. Revello-Chion, L. Galassi, P. Bianchi, G. Battelli, M. Coppa, E. Tabacco, and G. Borreani. 2016. Effect of milk thermisation and farming system on cheese sensory profile and fatty acid composition. Int. Dairy J. 59:10-19. https://doi.org/10.1016/ j.idairyj.2016.02.047.

Hurtaud, C., M. Dutreuil, M. Coppa, C. Agabriel, and B. Martin. 2014. Characterization of milk from feeding systems based on herbage or corn silage with or without flaxseed and authentication through fatty acid profile. Dairy Sci. Technol. 94:103-123. https:/ /doi.org/10.1007/s13594-013-0147-0.

INRA (Institut National de la Recherche Agronomique). 2018. Alimentation des ruminants. Quae, Versailles, Paris, France.

International Dairy Federation. 2000. Whole milk - Determination of milkfat, protein and lactose content - Guidance on the operation of mid-infrared instruments. IDF 141C:2000 (International Dairy Federation, Brussels, Belgium.).

Kennard, R. W., and L. A. Stone. 1969. Computer-aided design of experiments. Technometrics 11:137-148. https://doi.org/10.1080/ 00401706.1969 .10490666$.

Klaffenböck, M., A. Steinwidder, C. Fasching, G. Terler, L. Gruber, G. Mészáros, and J. Sölkner. 2017. The use of mid-infrared spectrometry to estimate the ration composition of lactating dairy cows. J. Dairy Sci. 100:5411-5421. https://doi.org/10.3168/jds.2016-12189.

Maurice-Van Eijndhoven, M. H. T., H. Soyeurt, F. Dehareng, and M. P. L. Calus. 2013. Validation of fatty acid predictions in milk using mid-infrared spectroscopy across cattle breeds. Animal 7:348-354. https://doi.org/10.1017/S1751731112001218.

McDermott, A., G. Visentin, S. McParland, D. P. Berry, M. A. Fenelon, and M. De Marchi. 2016. Effectiveness of mid-infrared spectroscopy to predict the color of bovine milk and the relationship between milk color and traditional milk quality traits. J. Dairy Sci. 99:3267-3273. https://doi.org/10.3168/jds.2015-10424.

Mitani, T., K. Kobayashi, K. Ueda, and S. Kondo. 2016. Discrimination of "grazing milk" using milk fatty acid profile in the grassland dairy area in Hokkaido. Anim. Sci. J. 87:233-241. https://doi.org/ 10.1111/asj.12422.

Nozière, P., B. Graulet, A. Lucas, B. Martin, P. Grolier, and M. Doreau. 2006. Carotenoids for ruminants: from forages to dairy products. Anim. Feed Sci. Technol. 131:418-450. https://doi.org/ 10.1016/j.anifeedsci.2006.06.018.

Ottavian, M., P. Facco, M. Barolo, P. Berzaghi, S. Segato, E. Novelli, and S. Balzan. 2012. Near-infrared spectroscopy to assist authentication and labeling of Asiago d'allevo cheese. J. Food Eng. 113:289-298. https://doi.org/10.1016/j.jfoodeng.2012.05.037.

Prache, S., B. Martin, and M. Coppa. 2020. Review: Authentication of grass-fed meat and dairy products from cattle and sheep. Animal 14:854-863. https://doi.org/10.1017/S1751731119002568.

Renna, M., A. Ferlay, C. Lucciana, D. Bany, B. Graulet, U. Wyss, S. Ravetto Enri, L. M. Battaglini, and M. Coppa. 2020. Relative hierarchy of farming practices affecting the fatty acid composition of permanent grasslands and of the derived bulk milk. Anim. Feed Sci. Technol. 267:114561.

Sanchez, M. P., M. El Jabri, S. Minéry, V. Wolf, E. Beuvier, C. Laithier, A. Delacroix-Buchet, M. Brochard, and D. Boichard. 2018.
Genetic parameters for cheese-making properties and milk composition predicted from mid-infrared spectra in a large data set of Montbéliarde cows. J. Dairy Sci. 101:10048-10061. https://doi .org/10.3168/jds.2018-14878.

Segato, S., G. Galaverna, B. Contiero, P. Berzaghi, A. Caligiani, A. Marseglia, and G. Cozzi. 2017. Identification of lipid biomarkers to discriminate between the different production systems for Asiago PDO cheese. J. Agric. Food Chem. 65:9887-9892. https://doi.org/ 10.1021/acs.jafc.7b03629.

Shenk, J. S., and M. O. Westerhaus. 1995. Analysis of agriculture and food products by near infrared reflectance spectroscopy. Monograph, NIR Systems Inc., Pennsylvania State University, and Owners of Infrasoft International, Silver Spring, MD.

Soyeurt, H., D. Bruwier, J.-M. Romnee, N. Gengler, C. Bertozzi, D. Veselko, and P. Dardenne. 2009. Potential estimation of major mineral contents in cow milk using mid-infrared spectrometry. J. Dairy Sci. 92:2444-2454. https://doi.org/10.3168/jds.2008-1734.

Soyeurt, H., F. Dehareng, N. Gengler, S. McParland, E. Wall, D. P. Berry, M. Coffey, and P. Dardenne. 2011. Mid-infrared prediction of bovine milk fatty acids across multiple breeds, production systems, and countries. J. Dairy Sci. 94:1657-1667. https://doi.org/ 10.3168/jds.2010-3408.

Toffanin, V., M. Penasa, S. McParland, D. P. Berry, M. Cassandro, and M. De Marchi. 2015. Genetic parameters for milk mineral content and acidity predicted by mid-infrared spectroscopy in Holstein-Friesian cows. Animal 9:775-780. https://doi.org/10.1017/ S1751731114003255.

Valdivielso, I., M. de Renobales, N. Aldai, and L. J. R. Barron. 2017. Changes in terpenoid composition of milk and cheese from commercial sheep flocks associated with seasonal feeding regimens throughout lactation. J. Dairy Sci. 100:96-105. https://doi.org/10 .3168/jds.2016-11761.

Valenti, B., L. Biondi, L. Campidonico, L. Bontempo, G. Luciano, F. Di Paola, V. Copani, L. Ziller, and F. Camin. 2017. Changes in stable isotope ratios in PDO cheese related to the area of production and green forage availability. The case study of Pecorino Siciliano. Rapid Commun. Mass Spectrom. 31:737-744. https:// doi.org/10.1002/rcm.7840.

Valenti, B., B. Martin, D. Andueza, C. Leroux, C. Labonne, F. Lahalle, H. Larroque, P. Brunschwig, C. Lecomte, M. Brochard, and A. Ferlay. 2013. Infrared spectroscopic methods for the discrimination of cows' milk according to the feeding system, cow breed and altitude of the dairy farm. Int. Dairy J. 32:26-32. https://doi.org/ 10.1016/j.idairyj.2013.02.014.

Vanlierde, A., H. Soyeurt, N. Gengler, F. G. Colinet, E. Froidmont, M. Kreuzer, F. Grandl, M. Bell, P. Lund, D. W. Olijhoek, M. Eugène, C. Martin, B. Kuhla, and F. Dehareng. 2018. Short communication: Development of an equation for estimating methane emissions of dairy cows from milk Fourier transform mid-infrared spectra by using reference data obtained exclusively from respiration chambers. J. Dairy Sci. 101:7618-7624. https://doi.org/10 .3168/jds.2018-14472.

Vicente, F., C. Santiago, J. D. Jiménez-Calderón, and A. MartínezFernández. 2017. Capacity of milk composition to identify the feeding system used to feed dairy cows. J. Dairy Res. 84:254-263. https://doi.org/10.1017/S0022029917000383. 